\title{
New Benzohydrazide Derivative as Corrosion Inhibitor for Carbon Steel in a 1.0 M HCl Solution: Electrochemical, DFT and Monte Carlo Simulation Studies
}

\author{
A. Chaouiki ${ }^{a, b}$, H. Lgaz ${ }^{a b}$, R. Salghi ${ }^{b, *}$, Santosh L. Gaonkar ${ }^{c}$,

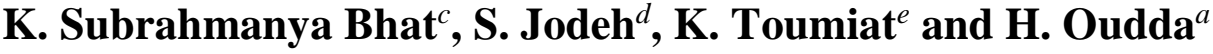 \\ ${ }^{a}$ Laboratory Separation Processes, Faculty of Science, Ibn Tofail University, \\ P.O. Box 242, Kenitra, Morocco \\ ${ }^{b}$ Laboratory of Environmental Engineering and Biotechnology, ENSA, Ibn Zohr University, \\ P.O. Box 1136, 80000 Agadir, Morocco \\ ${ }^{c}$ Department of Chemistry, Manipal Institute of Technology, \\ Manipal University, Manipal-576 104, India \\ ${ }^{d}$ Department of Chemistry, An-Najah National University, P.O. Box 7, Nablus, Palestine \\ ${ }^{e}$ Department of Materials Sciences, Laghouat University, P.O. Box 37, \\ 03000, Laghouat, Algeria
}

Received July 17, 2017; accepted April 1, 2018

\begin{abstract}
The present study aimed to evaluate the inhibition effect of an organic compound, namely, (E)-N'-(2-hydroxybenzylidene)isonicotinohydrazide (BIH), for carbon steel corrosion in a $1.0 \mathrm{M} \mathrm{HCl}$ solution, by using weight loss (WL), potentiodynamic polarization (PDP) and electrochemical impedance spectroscopy (EIS). Results show that $\mathrm{BIH}$ is a good inhibitor, and the percentage of inhibition efficiency increases on its higher concentrations. The maximum inhibition efficiency of $94 \%$ was obtained at $5 \times 10^{-3} \mathrm{M}$. Polarization studies revealed that the BIH compound acts as a mixed type inhibitor. EIS showed that increasing the concentration of the inhibitor led to an increase in the charge transfer resistance and a decrease in the double layer capacitance. It was found that the adsorption of this compound obeyed the Langmuir adsorption isotherm. The associated activation energies and thermodynamic parameters of the adsorption process were evaluated and discussed. The temperature effect was studied in the range from 303 to $333 \mathrm{~K}$. In addition, quantum chemical calculations based on the density function theory (DFT) and Monte Carlo simulations were done to support the experimental results.
\end{abstract}

Keywords: benzohydrazide derivative; corrosion inhibition; carbon steel; $\mathrm{HCl}$; DFT; Monte Carlo simulations.

\footnotetext{
* Corresponding author. E-mail address: r.salghi@uiz.ac.ma
} 


\section{Introduction}

Nowadays, metals and their alloys are widely used in various technological and industrial applications, due to their excellent structural and mechanical strength [1-14]. Hydrochloric acid and sulfuric acid are most commonly used at various industrial processes, such as steel acid pickling, scale removal in metallurgy, boilers acid cleaning and oil-well acidizing [15-18].The metal dissolution in the corrosive media is not only a source of raw materials wastage and energy, but also contributes to environmental pollution. In terms of corrosion protection, it is possible to act on the material itself, on its surface, and on the environment with which it is in contact. Therefore, the special importance of corrosion inhibitors is more pronounced, and many scientists are conducting research on this topic. The chemical compounds used as corrosion inhibitors are considered as some of the most used substances for reducing the dissolution of various metals and, consequently, to raise their cycle life. The selection of a good corrosion inhibitor is controlled by its economical availability, its efficiency to inhibit the substrate material and its environmental side effects. Most organic substances employed as corrosion inhibitors can adsorb onto the metal surface through heteroatom's such as nitrogen, oxygen, sulfur and phosphorus, as well as multiple bonds or aromatic rings [19-20]. These organic inhibitors are usually adsorbed onto the metal surface via the formation of a coordinate covalent bond (chemical adsorption) or the electrostatic interaction between the metal and the inhibitor (physical adsorption), and sometimes following both routes, thus preventing metallic dissolution in acidic media [21]. The constituents of the metal and its alloys, the inhibitor concentration and structure, and the metal environment temperature, are notable factors that determine the extent of the adsorption which, in its turn, dictates the inhibition efficiency [22].

The aim of the present work was to study the inhibition efficiencies of (E)-N'-(2 hydroxybenzylidene)isonicotinohydrazide on carbon steel corrosion in a $1.0 \mathrm{M}$ $\mathrm{HCl}$ solution, using electrochemical techniques such as potentiodynamic polarization (PDP), electrochemical impedance spectroscopy (EIS) and weight loss (WL) measurements. The temperature effect on the efficiency of this inhibitor for carbon steel corrosion in a 1.0 M HC1 solution, in the range of 303$333 \mathrm{~K}$, has been systematically studied.

Besides that, quantum chemical calculations and Monte Carlo simulations studies were also carried out to provide more insights into the theoretical explanations of the studied compound's inhibition activities. They can also be utilized to add theoretical support to the experimental results [23-24]. The structural formula of the examined inhibitor is shown in Fig. 1.

\section{Experimental details \\ Synthesis}

(E)-N'-(2-hydroxybenzylidene)isonicotinohydrazide 4 was prepared as follows: isonicotinic acid $1(1 \mathrm{~g}, 8.1 \mathrm{mmol})$ in ethanol $(3 \mathrm{~mL})$ and conc. $\mathrm{H}_{2} \mathrm{SO}_{4}(1 \mathrm{~mL})$ were refluxed for 2 hours under stirring. This reaction mixture was cooled down to $15{ }^{\circ} \mathrm{C}$, using an ice-water bath. With stirring, sodium carbonate $(2.15 \mathrm{~g})$ was 
carefully added to get a $\mathrm{pH}$ value between 8 and 9. The temperature during neutralization was maintained between 5 and $10{ }^{\circ} \mathrm{C}$. The solid was filtered, and the filtrate was extracted with ethyl acetate. The solvent was removed to get ethyl isonicotinate. The obtained ethyl isonicotinate was dissolved in ethanol (3 $\mathrm{mL})$ in a round bottomed flask, and hydrazine hydrate $(0.5 \mathrm{~g})$ was added. The mixture was refluxed for two hours. The reaction mixture was cooled, and the product was isolated by suction filtration, to give hydrazine derivative 3 . The crude product was recrystallized using ethanol as a solvent. The product yield was $0.8 \mathrm{~g}$, and its melting point was around $172^{\circ} \mathrm{C}$.

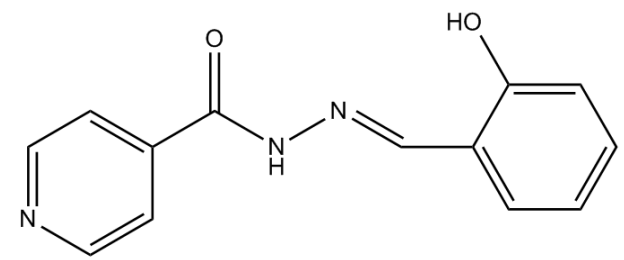

Figure 1. Chemical structure of (E)-N'-(2-hydroxybenzylidene)isonicotinohydrazide (BIH).

An equimolar mixture of hydrazine derivative $3(0.1 \mathrm{~g}, 7.3 \mathrm{mmol})$ and salicylaldehyde $(0.1 \mathrm{~g}, 7.3 \mathrm{mmol})$ was dissolved in IPA/AcOH $(0.5 \mathrm{~mL})$, in a conical flask. The mixture was stirred at $70^{\circ} \mathrm{C}$, for 2 hours. The reaction mixture mass was cooled, then, the formed solid was filtered and recrystallized using methanol as a solvent, to get $0.14 \mathrm{~g}$ of isonicotinohydrazide derivative 4 , with a yield of around $80 \%$ (Scheme 1).
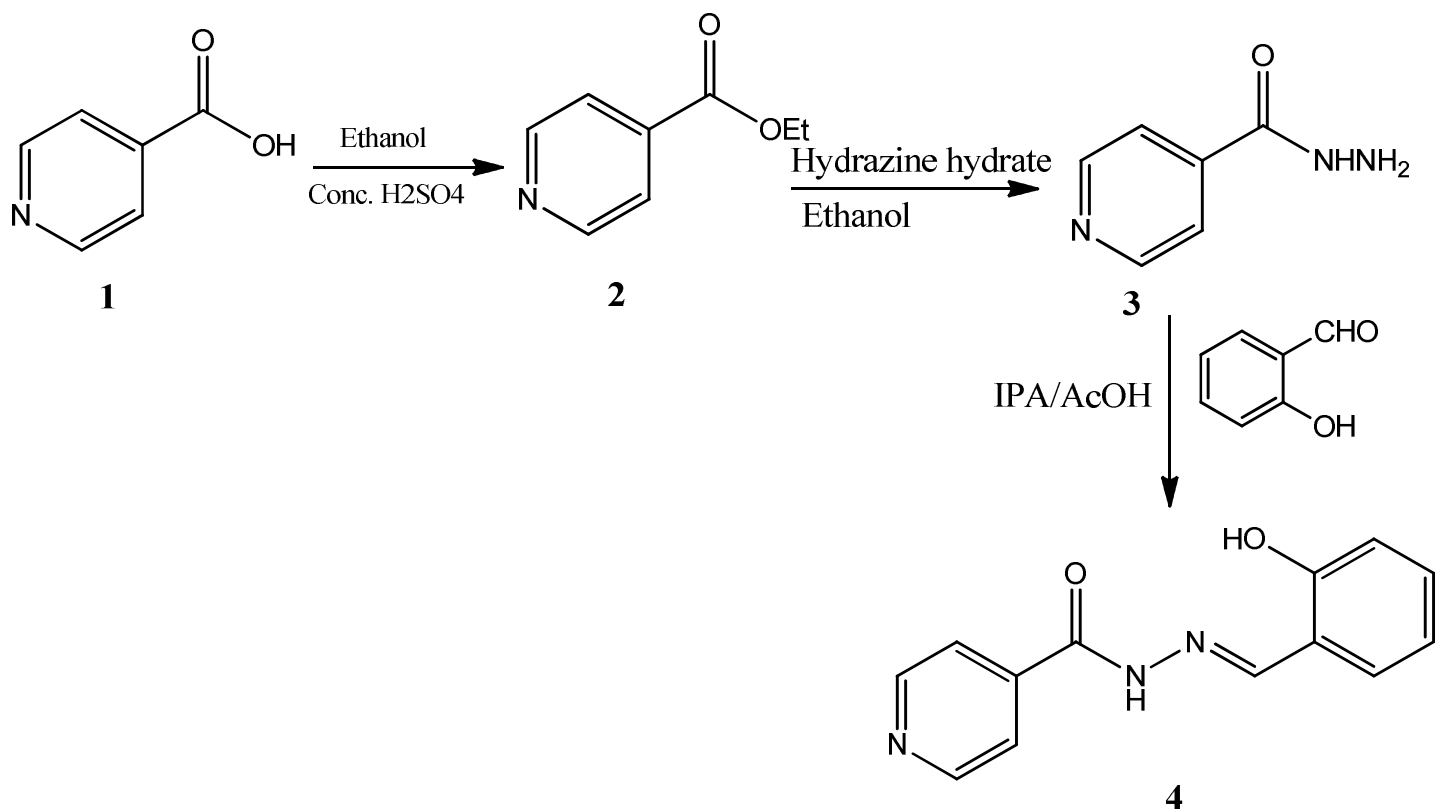

Scheme 1. Synthesis of (E)-N'-(2-hydroxybenzylidene) isonicotinohydrazide.

White crystals yield $0.14 \mathrm{~g}, \mathrm{mp} 262-264{ }^{\circ} \mathrm{C}, \mathrm{IR}\left(\mathrm{V}_{\max }, \mathrm{cm}^{-1}, \mathrm{KBr}\right): 3344(-\mathrm{OH})$, $3178(\mathrm{NH}), 3004(-\mathrm{CH}), 1685$ (amide $\mathrm{C}=\mathrm{O}$ ), 1566 (imine $\mathrm{C}=\mathrm{N}$ ). ${ }^{1} \mathrm{H}$ NMR (400 MHz, DMSO-d6): $\delta$ ppm $11(\mathrm{~s}, \mathrm{OH}), 8.8-8.9(\mathrm{~d}$, pyridine $2 \mathrm{H}), 8.6-8.8(\mathrm{~d}$, 
pyridine $2 \mathrm{H}), 8.7(\mathrm{~s}, \mathrm{CH}), 7.5-7.6(\mathrm{~d}$, aromatic1H), $8.6(\mathrm{~s}, \mathrm{NH}), 6.8-7.0(\mathrm{~d}$, aromatic $2 \mathrm{H}), 7.3-7.4(\mathrm{~m}$, aromatic $1 \mathrm{H})$.

\section{Materials}

The steel used in this study was carbon steel (Euronorm: C35E carbon steel and US specification: SAE 1035) with a chemical composition (in wt $\%$ ) of $0.370 \%$ C, $0.230 \% \mathrm{Si}, 0.680 \% \mathrm{Mn}, 0.016 \% \mathrm{~S}, 0.077 \% \mathrm{Cr}, 0.011 \% \mathrm{Ti}, 0.059 \% \mathrm{Ni}$, $0.009 \% \mathrm{Co}, 0.160 \% \mathrm{Cu}$, and the remainder iron $(\mathrm{Fe})$. The carbon steel samples were pretreated prior to the experiments: they were grinded with emery paper SiC (320, 800 and 1200), rinsed with distilled water, degreased in acetone, washed again with bidistilled water, and then dried at room temperature before use.

\section{Solutions}

The aggressive solutions of $1.0 \mathrm{M} \mathrm{HCl}$ were prepared by dilution of analytical grade $37 \% \mathrm{HCl}$ with distilled water. The used concentration range of (E)-N'-(2hydroxybenzylidene) isonicotinohydrazide was from $5 \times 10^{-3}$ to $1 \times 10^{-4} \mathrm{M}$.

\section{Weight loss measurements}

The gravimetric measurements were performed by immersing the carbon steel samples in a 1.0 M HC1 solution, without and with different concentrations of the studied inhibitor, for 6.0 hours, at $303 \mathrm{~K}$. The carbon steel specimens had a rectangular form [2 $\left.\mathrm{x} 2 \times 0.08\left(\mathrm{~cm}^{3}\right)\right]$. Gravimetric experiments were carried out in a double walled glass cell equipped with a thermo stated cooling condenser containing $80 \mathrm{~mL}$ of the non-de-aerated test solution. After completion of the immersion time, the specimens were taken out, washed with double distilled water, degreased with acetone, dried and, finally, accurately weighed using an analytical balance (precision $\pm 0.1 \mathrm{mg}$ ). All weight loss experiments were triply performed, and the mean value was reported, to insure the results reproducibility.

\section{Electrochemical measurements}

All the electrochemical studies were carried in a corrosion cell kit with a three electrode configuration. The reference electrode was a saturated calomel electrode (SCE). A platinum electrode was used as auxiliary electrode. The working electrode was carbon steel. All potentials given in this study were referred to this reference electrode (SCE). The working electrode was immersed in the test solution for $30 \mathrm{~min}$, to establish steady state open circuit potential $\left(\mathrm{E}_{\mathrm{ocp}}\right)$. After obtaining OCP, the electrochemical measurements were performed. All electrochemical tests have been performed in aerated solutions at $303 \mathrm{~K}$. The system impedance was measured as a function of the frequency of the applied signal, and its value is given in the complex plane for each frequency. The electrochemical impedance spectroscopy (EIS) tests were carried out at open circuit potential (OCP), in the frequency range from $10 \mathrm{kHz}$ to 100 $\mathrm{mHz}$, with a signal amplitude of $10 \mathrm{mV}$, using a Voltalab (PGZ 100) Potentiostat/Galvanostat coupled to a computer equipped with Voltamaster 4 software. 
The current-potential curves were obtained by potentiodynamic mode in the 1.0 $\mathrm{M} \mathrm{HCl}$ solution, with different concentrations of the tested inhibitor, by automatically changing the electrode potential from $-800 \mathrm{mV}$ to $-200 \mathrm{mV}$ vs. the saturated calomel electrode, with a potential scan rate of $1 \mathrm{mV} / \mathrm{s}$, and the Tafel method allowed us to determine the corrosion current value and other electrochemical parameters.

\section{Quantum chemical study}

The geometric optimization and quantum chemical computations of the investigated molecule were performed using DFT (density functional theory), with the help of the Becke three-parameter hybrid functional, together with the Lee-Yang-Paar correlation functional (B3LYP) [25]. The 6-31G(d, p) basis set that was chosen for all the calculations was implemented in Gaussian 09 software for Windows [26]. This basis set gives good geometry optimizations. Theoretical chemical parameters, such as the energies of the highest occupied $\left(\mathrm{E}_{\mathrm{HOMO}}\right)$ and the lowest unoccupied molecular orbitals ( $\left.\mathrm{E}_{\mathrm{LUMO}}\right)$, energy gap $(\Delta \mathrm{E})$ between LUMO and HOMO, and the fraction of electrons transferred $(\Delta \mathrm{N})$ for the BIH inhibitor were calculated from the obtained optimized structure.

The ionization potential (IP) and electron affinity (EA) of the inhibitors were calculated using the following equations:

$$
\begin{aligned}
& I P=-E_{\mathrm{HOMO}} \\
& E A=-E_{\mathrm{LUMO}}
\end{aligned}
$$

Mulliken electronegativity $(\chi)$ and absolute hardness $(\eta)$ can be approximated using the following equations [27-28]:

$$
\begin{aligned}
& \chi=\frac{I P+E A}{2} \\
& \eta=\frac{I P-E A}{2}
\end{aligned}
$$

The number of transferred electrons $(\Delta N)$ was calculated by application of the Pearson method, using the following equation [29]:

$$
\Delta N=\frac{\phi-\chi_{\text {inh }}}{2\left(\eta_{F e}+\eta_{\text {inh }}\right)}
$$

where $\phi$ and $\chi_{\text {inh }}$ denote the work function and absolute electronegativity of iron and the inhibitor molecule, respectively. $\eta_{\mathrm{Fe}}$ and $\eta_{\text {inh }}$ denote the absolute hardness of iron and of the inhibitor molecule, respectively. A theoretical value $\left(\eta_{\mathrm{Fe}}=0\right)$ is frequently used (since, for bulk metallic atoms, $\mathrm{I}=\mathrm{A}$ ). The obtained DFT derived $\phi$ values for Fe $\left(\begin{array}{lll}1 & 0 & 0\end{array}\right), \mathrm{Fe}\left(\begin{array}{lll}1 & 1 & 0\end{array}\right)$ and Fe $\left(\begin{array}{lll}1 & 1 & 1\end{array}\right)$ surfaces are 3.91, 4.82 and $3.88 \mathrm{eV}$, respectively [30-31]. Fe ( $\left.\begin{array}{lll}1 & 1 & 0\end{array}\right)$ was the only surface used in this study, due to its higher stabilization energy, and to the packed surface [32]. 


\section{Monte Carlo simulations}

The Monte Carlo (MC) search was adopted to compute the low configuration adsorption energy of BIH interactions on a clean iron surface. The Monte Carlo simulation was carried out using Materials Studio 6.0 software (Accelrys, Inc.) [26]. The Fe crystal was cleaved along the (llll 10 ) plane, being the most stable surface, as reported in the literature. Then, the Fe $\left(\begin{array}{lll}1 & 1 & 0\end{array}\right)$ plane was enlarged to a (12x12) supercell, to provide a large surface for the inhibitor interaction. The simulation of the interaction between BIH and the Fe $\left(\begin{array}{lll}1 & 1 & 0\end{array}\right)$ surface was carried out in a simulation box $(19.85 \times 19.85 \times 38.11 \AA)$, with periodic boundary conditions, which modeled a representative part of the interface devoid of any arbitrary boundary effects. After that, a vacuum slab with $50 \AA$ thickness was built above the Fe ( $\left.\begin{array}{lll}1 & 1 & 0\end{array}\right)$ plane. All simulations were implemented with the COMPASS force field, to optimize the structures of all components of the system of interest. More simulation details on the methodology of Monte Carlo simulations can be found in previous publications [29-31].

\section{Results and discussion}

\section{Concentration effect}

Weight loss measurements

The effect of the BIH inhibitor concentration on carbon steel samples corrosion in a $1.0 \mathrm{M} \mathrm{HCl}$ solution was studied using weight loss measurements at $303 \mathrm{~K}$, for 6 hours immersion time. The obtained data are listed in Table 1.The inhibition efficiency $\left(\eta_{\mathrm{WL}}(\%)\right)$ and the surface coverage $(\theta)$ values were determined from the corrosion rate, using the following equations:

$$
\begin{gathered}
\eta_{W L}(\%)=\left[\frac{W^{\circ}-W}{W^{\circ}}\right] \times 100 \\
\theta=\left[\frac{W^{\circ}-W}{W^{\circ}}\right]
\end{gathered}
$$

where $W^{\circ}$ and $W$ are carbon steel corrosion rate in $1.0 \mathrm{M} \mathrm{HC1}$, without and with different inhibitor concentrations, respectively.

Table 1. Effect of BIH concentrations on the corrosion data of carbon steel, in a 1.0 $\mathrm{M} \mathrm{HCl}$ solution.

\begin{tabular}{ccccc}
\hline Inhibitor & $\begin{array}{c}\text { Concentration } \\
(\mathbf{M})\end{array}$ & $\begin{array}{c}\mathbf{W} \\
\left(\mathbf{m g} / \mathbf{c m}^{2} \times \mathbf{h}\right)\end{array}$ & $\eta_{W L}(\%)$ & $\boldsymbol{\theta}$ \\
\hline Blank & 1.0 & 1.135 & - & - \\
\hline \multirow{3}{*}{ BIH } & $5 \times 10^{-3}$ & 0.079 & 93 & 0.93 \\
& $1 \times 10^{-3}$ & 0.113 & 90 & 0.90 \\
& $5 \times 10^{-4}$ & 0.185 & 86 & 0.86 \\
& $1 \times 10^{-4}$ & 0.227 & 80 & 0.80 \\
\hline
\end{tabular}


From the results depicted in Table 1, it is clearly noticed that the inhibition efficiency $\left(\eta_{\mathrm{WL}}(\%)\right)$ increased with an increasing inhibitor concentration and, at $5 \times 10^{-3} \mathrm{M}$ concentration, BIH exhibited a maximum inhibition efficiency $(93 \%)$, which represents an excellent corrosion inhibition. On the other hand, it is also clearly noticed from Fig. 2 that carbon steel corrosion rate (W) decreased with an increasing inhibitor concentration. This behavior can be attributed to the increase in $\mathrm{BIH}$ adsorption at the metal/solution interface, as its concentration increased [37]. In the inhibitor absence, the corrosion rate was as high as $1.135 \mathrm{mg} \mathrm{cm}^{-2} \mathrm{~h}^{-1}$ and, in presence of $5 \times 10^{-3} \mathrm{M}$ of the inhibitor, this value was reduced to $0.079 \mathrm{mg} \mathrm{cm}^{-2} \mathrm{~h}^{-1}$. This phenomenon may be due to the adsorption of the tested compound onto the metal surface, through $\pi$-electrons of the aromatic ring and a lone pair of electrons of $\mathrm{N}$ and $\mathrm{O}$ atoms [38].

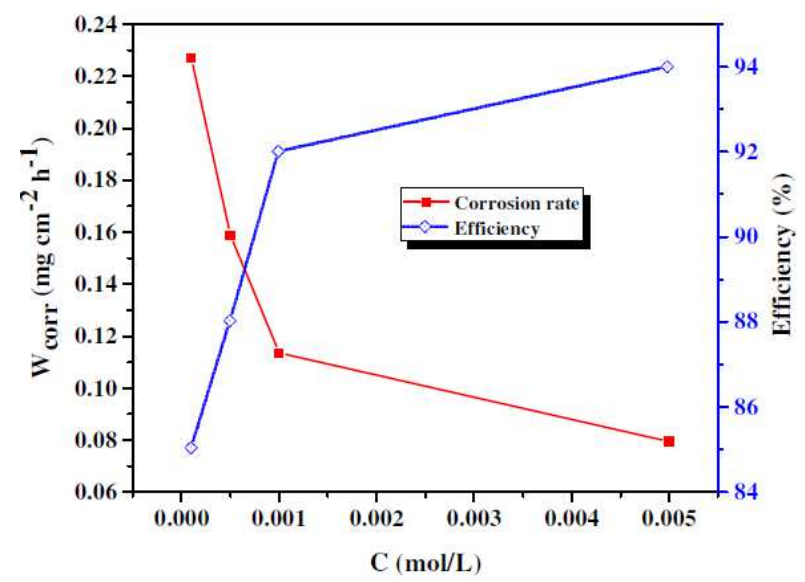

Figure 2. Relationship between the inhibition efficiency, corrosion rate and inhibitor concentration for carbon steel, after 6 hours of immersion time in a $1.0 \mathrm{M} \mathrm{HC} 1$ solution, at $303 \mathrm{~K}$.

\section{Tafel polarization study}

Fig. 3 shows the potentiodynamic polarization curves for carbon steel corrosion in a $1.0 \mathrm{M} \mathrm{HCl}$ solution, without and with different BIH concentrations, at 303 $\mathrm{K}$. Electrochemical parameters such as corrosion potential ( $\left.\mathrm{E}_{\mathrm{corr}}\right)$, corrosion current density ( $\left.i_{\text {corr }}\right)$, anodic Tafel slope $\left(\beta_{a}\right)$, cathodic Tafel slope $\left(\beta_{c}\right)$ and percentage inhibition efficiency were determined and summarized in Table 2.The $\mathrm{i}_{\text {corr }}$ values were used to calculate the inhibition efficiency $\eta_{\text {PDP }}(\%)$, using equation 8:

$$
\eta_{\mathrm{PDP}}(\%)=\left[1-\frac{i_{\text {corr }}}{i_{\text {corr }}^{\circ}}\right] \times 100
$$

where $i_{\text {corr }}$ and $i_{\text {corr }}^{\circ}$ are the corrosion current densities in inhibited and uninhibited media, respectively.

It is clearly noticed from Fig. 3 that the anodic and cathodic current densities effectively decreased as the BIH concentration in the acidic solution increased and, generally, with a slight shift in the $E_{\text {corr }}$ values, suggesting that the inhibitor molecules retarded the corrosion process. In the acidic media, carbon steel 
oxidative dissolution in the anodic region, and hydrogen reduction in the cathodic region are observed in the Tafel plots. In addition, the parallel cathodic Tafel curves in Fig. 3 show that the hydrogen evolution was activationcontrolled, and that the reduction mechanism was not affected by the inhibitor presence [39].

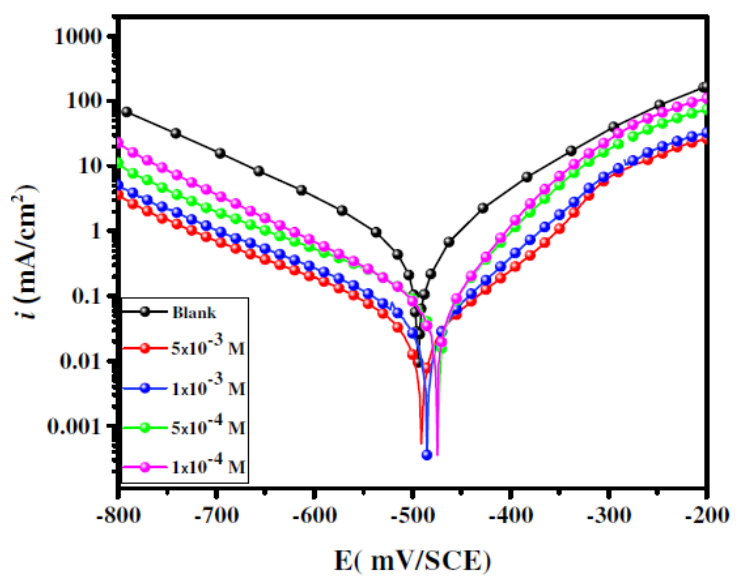

Figure 3. Potentiodynamic polarization curves of carbon steel in a $1.0 \mathrm{M} \mathrm{HCl}$ solution, in the presence and absence of different $\mathrm{BIH}$ concentrations, at $303 \mathrm{~K}$.

Table 2. Carbon steel PDP parameters at various BIH concentrations in a $1.0 \mathrm{M}$ $\mathrm{HCl}$ solution, and the corresponding inhibition efficiency, at $303 \mathrm{~K}$.

\begin{tabular}{ccccccc}
\hline Inhibitor & $\begin{array}{c}\text { Concentration } \\
(\mathbf{M})\end{array}$ & $\begin{array}{c}-\boldsymbol{E}_{\mathbf{c o r r}} \\
(\mathbf{m V / S C E})\end{array}$ & $\begin{array}{c}-\boldsymbol{\beta}_{\mathbf{c}} \\
(\mathbf{m V / d e c})\end{array}$ & $\begin{array}{c}\boldsymbol{\beta} \text { a } \\
(\mathbf{m V / d e c})\end{array}$ & $\begin{array}{c}\boldsymbol{i}_{\text {corr }} \\
\left(\boldsymbol{\mu} \mathbf{A} / \mathbf{c m}^{\mathbf{2}}\right)\end{array}$ & $\begin{array}{c}\boldsymbol{\eta}_{\boldsymbol{P D P} \boldsymbol{P}} \\
(\boldsymbol{\%})\end{array}$ \\
\hline Blank & 1.0 & 496 & 162 & 132.2 & 564 & - \\
\hline \multirow{3}{*}{ BIH } & $5 \times 10^{-3}$ & 493 & 164 & 89 & 49 & 91 \\
& $1 \times 10^{-3}$ & 487 & 166 & 88 & 61 & 89 \\
& $5 \times 10^{-4}$ & 477 & 161 & 73 & 81 & 85 \\
& $1 \times 10^{-4}$ & 476 & 163 & 72 & 99 & 82 \\
\hline
\end{tabular}

By inspecting the results in Table 2 , we note that $i_{\text {corr }}$ considerably decreased with an increasing $\mathrm{BIH}$ concentration. It is reported in literature that, if the displacement in $\mathrm{E}_{\text {corr }}$, in the inhibitor presence, as compared to blank solution, is greater than $\pm 85 \mathrm{mV}$, the inhibitor is classified as of the cathodic or anodic type [40]. In the presence of this compound, carbon steel corrosion potential only shifted $20 \mathrm{mV}$ to the negative side. Therefore, it could be concluded that this compound $(\mathrm{BIH})$ is of the mixed-type inhibitor for carbon steel in a $1.0 \mathrm{M} \mathrm{HCl}$ solution; $i_{\text {corr }}$ reached a value of $49 \mu \mathrm{A} / \mathrm{cm}^{2}$, at an inhibitor concentration of $5 \times 10^{-3} \mathrm{M}$. This $i_{\text {corr }}$ value led to a maximum $\eta \%$ value of about $91 \%$.

Further, it can be observed from the results shown in Table 2 that the values of the cathodic $(\beta \mathrm{c})$ and anodic $(\beta \mathrm{a})$ Tafel lines show slight changes with BIH presence. These results suggest that the surface blocking effect of the adsorbed BIH diminished the anodic and cathodic reactions [41]. 


\section{Electrochemical impedance spectroscopy (EIS) study}

In order to have more information on the phenomenon of carbon steel corrosion inhibition in a $1.0 \mathrm{M}$ solution, impedance measurements were performed in the Nyquist plan, in the absence and presence of different inhibitor concentrations, at $303 \mathrm{~K}$, for an exposure time of $30 \mathrm{~min}$. The Nyquist plots are shown in Fig. 4.

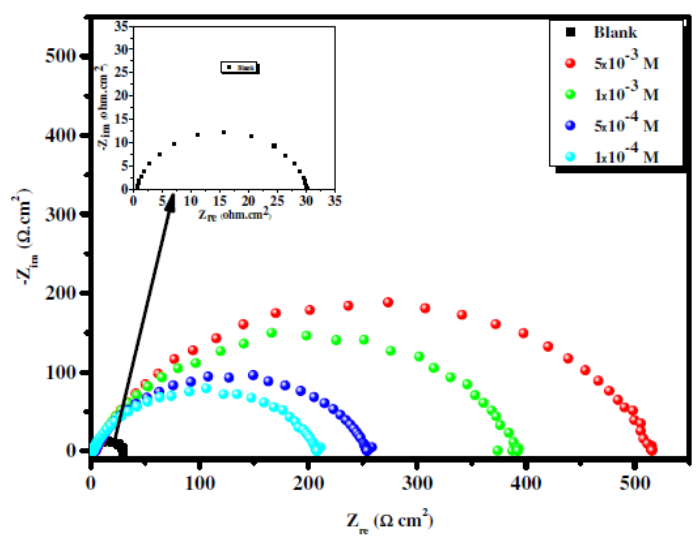

Figure 4. Nyquist diagrams for the carbon steel electrode in a $1.0 \mathrm{M} \mathrm{HCl}$ solution with different BIH inhibitor concentrations.

It is clear from this figure that the impedance response of carbon steel significantly changed after $\mathrm{BIH}$ addition, and that all impedance spectra exhibited one single depressed capacitive loop at the higher frequency range. This depression is often associated to the non-homogeneity and roughness of the carbon steel surface [42]. Further, it was also observed that the impedance modulus gradually increased with increasing inhibitor concentrations; this suggests that the formed inhibitive film was strengthened by $\mathrm{BIH}$ addition. Generally, loop-like capacitive EIS plots are mainly attributed to the charge transfer process, while the increase in the semicircle diameter with a rise in BIH concentration is the result of the inhibitor adsorption onto the carbon steel surface [43]. The experimental data were fitted by a Zview software, and an electrical equivalent-circuit diagram corresponding to the metal/solution interface was proposed (Fig. 5). Impedance parameters such as the charge transfer resistance $\left(R_{c t}\right)$ - whose value is a measure of electron transfer across the surface ,$- C_{\mathrm{dl}}$ values, and the compound's efficiency values corresponding to various concentrations, are presented in Table 3. Double layer capacitance values were obtained using the following equation:

$$
C_{\mathrm{dl}}=\sqrt[n]{Q \times R_{\mathrm{ct}}^{1-\mathrm{n}}}
$$

where $\mathrm{Q}$ is the CPE constant and $\mathrm{n}$ is a coefficient that can be used as a measure of surface inhomogeneity [44].

The inhibition efficiency was calculated using the charge transfer resistance as follows:

$$
\eta_{E I S}(\%)=\left[\frac{R_{\mathrm{ct}(\mathrm{inh})}-R_{\mathrm{ct}}}{R_{\mathrm{ct}(\mathrm{inh})}}\right] \times 100
$$


where $R_{c t(i n h)}$ and $R_{c t}$ are the charge transfer resistance values, with and without $\mathrm{BIH}$, respectively.

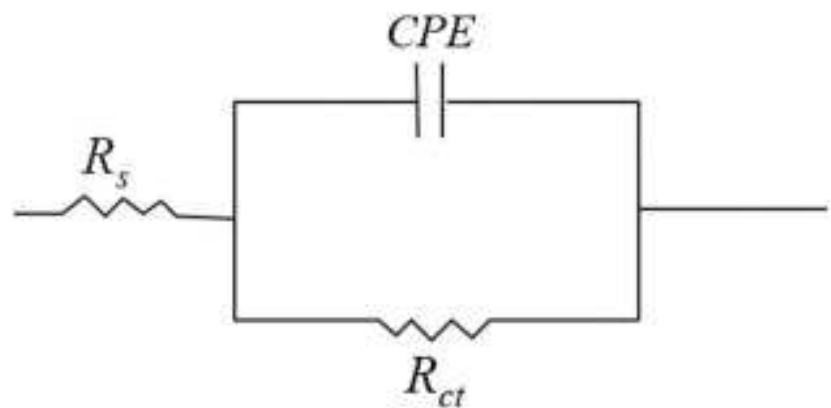

Figure 5. Equivalent circuit applied for fitting of the impedance spectra.

Table 3. EIS parameters for carbon steel corrosion in a $1.0 \mathrm{M} \mathrm{HCl}$ solution with various $\mathrm{BIH}$ concentrations, at $303 \mathrm{~K}$.

\begin{tabular}{|c|c|c|c|c|c|c|}
\hline Inhibitor & $\begin{array}{c}\text { Concentration } \\
(\mathrm{M})\end{array}$ & $\begin{array}{c}R_{\mathrm{ct}} \\
\left(\mathbf{\Omega \times \mathbf { c m } ^ { 2 }}\right) \\
\end{array}$ & $n$ & $\begin{array}{c}\mathrm{Q} \times 10^{-4} \\
\left(\mathrm{~s}^{\mathrm{n}} / \mathbf{\Omega} \times \mathrm{cm}^{2}\right) \\
\end{array}$ & $\begin{array}{c}C_{\mathrm{dl}} \\
\left(\mu \mathrm{F} / \mathrm{cm}^{2}\right)\end{array}$ & $\begin{array}{l}\eta_{\text {Ret }} \\
(\boldsymbol{\%})\end{array}$ \\
\hline Blank & 1.0 & 29.35 & 0.89 & 1.7610 & 91 & - \\
\hline \multirow{4}{*}{ BIH } & $5 \times 10^{-3}$ & 511.7 & 0.79 & 0.3236 & 11 & 94 \\
\hline & $1 \times 10^{-3}$ & 389 & 0.80 & 0.3641 & 13 & 92 \\
\hline & $5 \times 10^{-4}$ & 250.5 & 0.81 & 0.4538 & 16 & 88 \\
\hline & $1 \times 10^{-4}$ & 206.2 & 0.81 & 0.6558 & 24 & 85 \\
\hline
\end{tabular}

By inspection of the results shown in Table 3 , it can be noticed that $R_{c t}$ values increased, while $\mathrm{C}_{\mathrm{dl}}$ values decreased with higher inhibitor concentrations, suggesting, in the present study, that BIH adsorbed onto the carbon steel surface, and formed an insulating protective film [45]. In addition, the decrease in CPE can result from a decrease in the local dielectric constant, and from an increase in the thickness of the electrical double layer, due to the inhibitor molecules adsorption at the metal/solution interface [46]. The results also show that at the concentration of $5 \times 10^{-3} \mathrm{M}$, the percentage of inhibition efficiency reaches the highest value (94\%). The $\eta \%$ values obtained in the EIS study were in good correlation with those obtained from the weight loss and PDP studies.

\section{Effect of solution temperature}

It is essential to study the temperature effect on carbon steel corrosion in a $1.0 \mathrm{M}$ $\mathrm{HCl}$ solution, in the absence and presence of $5 \times 10^{-3} \mathrm{M}$ concentration, at temperatures ranging from 303 to $333 \mathrm{~K}$, because many changes occur on the metal surface, such as rapid etching, desorption of some inhibitor molecules and of the inhibitor itself [47]. For the studied inhibitor, potentiodynamic polarization measurements (Figs. 6 and 7) were performed, to investigate the temperature effect on the inhibition efficiency, and to calculate activation parameters. The results are given in Table 4 . It can be seen from the results that $\eta \%$ decreased with increased solution temperatures, from 303 to $333 \mathrm{~K}$. This is due to an appreciable decrease in the inhibitor adsorption molecules onto the metal surface, with a rise in temperature, which further causes inhibitor molecules desorption from carbon steel surface. It is also clear from Table 4 that the corrosion rate 
increased with increased temperatures, both in uninhibited and inhibited solutions. From this table, it is also obvious that carbon steel corrosion rate slowly increased in the inhibitor presence, as compared to without inhibitor. These results confirm that $\mathrm{BIH}$ acts as an efficient inhibitor for carbon steel in a 1.0 $\mathrm{M} \mathrm{HCl}$ solution, in the studied temperature range.

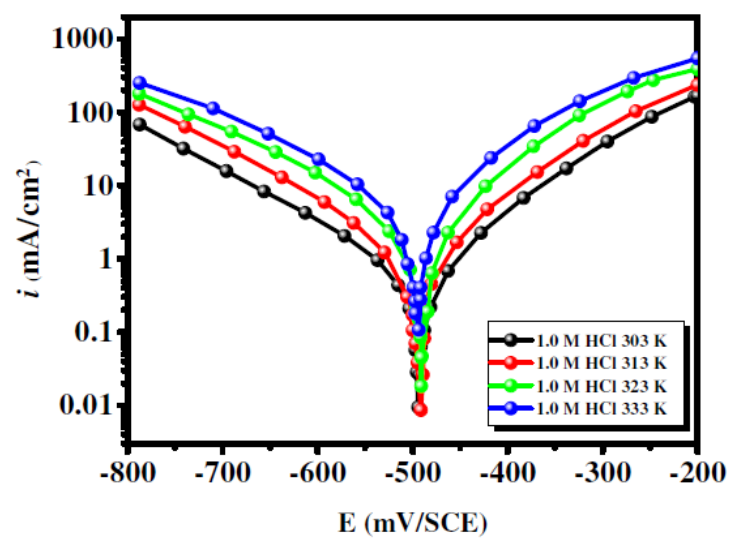

Figure 6. Potentiodynamic polarization curves of carbon steel in a $1.0 \mathrm{M} \mathrm{HCl}$ solution, at different temperatures.

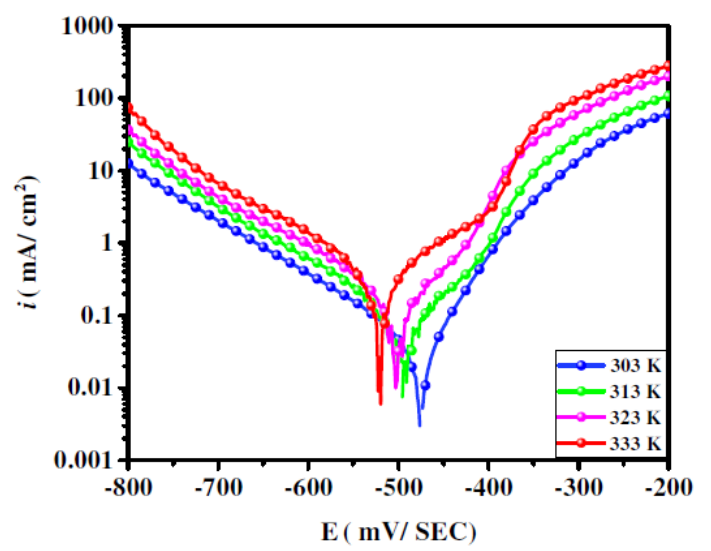

Figure 7. Potentiodynamic polarization curves of carbon steel in a $1.0 \mathrm{M} \mathrm{HCl}$ solution, in the presence of $5 \times 10^{-3} \mathrm{M}$ of $\mathrm{BIH}$, at different temperatures.

In addition, the temperature effect on the nature of carbon steel dissolution in a 1.0 $\mathrm{M} \mathrm{HCl}$ solution can be best explained in terms of Arrhenius equation, where the natural logarithm of $i_{\text {corr }}$ is a linear function of $1 / T$. The corresponding relation (11) provides access to the activation energies [48-49].

$$
i_{\text {corr }}=\operatorname{kexp}\left(\frac{- \text { Ea }}{\mathrm{RT}}\right)
$$

To access the thermodynamic characteristics - enthalpy of activation $\left(\Delta \mathrm{H}_{\mathrm{a}}{ }^{0}\right)$ and entropy of activation $\left(\Delta \mathrm{S}_{\mathrm{a}}{ }^{0}\right)-$ we used the Arrhenius transition equation [50],

$$
i_{\text {corr }}=\left(\frac{R T}{N h}\right) \exp \left(\frac{\Delta \mathrm{Sa}^{\circ}}{R}\right) \exp \left(\frac{-\Delta \mathrm{Ha}^{\circ}}{R T}\right)
$$

where $\mathrm{k}$ is the Arrhenius pre-exponential factor (what $\mathrm{k}$ ?), $\mathrm{T}$ is the absolute temperature, $E_{a}$ is the activation corrosion energy for the corrosion process, $h$ is 
the Planck's constant, $\mathrm{N}$ is the Avogadro's number, $\Delta \mathrm{S}_{\mathrm{a}}{ }^{0}$ is the entropy of activation, and $\Delta \mathrm{H}_{\mathrm{a}}{ }^{0}$ is the enthalpy of activation.

Table 4. The influence of temperature on the electrochemical parameters for a carbon steel electrode immersed in a $1.0 \mathrm{M} \mathrm{HCl}$ solution, and $1.0 \mathrm{M} \mathrm{HCl}+5 \times 10^{-3} \mathrm{M}$ of $\mathrm{BIH}$.

\begin{tabular}{cccccc}
\hline Inhibitor & $\begin{array}{c}\text { Temperature } \\
(\mathrm{K})\end{array}$ & $\begin{array}{c}-\boldsymbol{E}_{\mathbf{c o r r}} \\
(\mathbf{m V} / \mathbf{S C E})\end{array}$ & $\begin{array}{c}\boldsymbol{- \beta \mathbf { c }} \\
\left(\mathbf{m V} \mathbf{d e s}^{-\mathbf{1}}\right)\end{array}$ & $\begin{array}{c}\boldsymbol{i}_{\text {corr }} \\
\left(\boldsymbol{\mu} \mathbf{A} \mathbf{~ c m}^{-\mathbf{2}}\right)\end{array}$ & $\begin{array}{c}\mathbf{H} \\
(\boldsymbol{\%})\end{array}$ \\
\hline \multirow{3}{*}{ Blank } & 303 & 496 & 162.5 & 564 & - \\
& 313 & 498 & 154.5 & 773 & - \\
& 323 & 492 & 176.0 & 1244 & - \\
& 333 & 497 & 192.0 & 1650 & - \\
$5 \times 10^{-3} \mathbf{M}$ & 303 & 493.1 & 184.2 & 49 & 91 \\
BIH & 313 & 498.6 & 130.9 & 87 & 88 \\
& 323 & 504.9 & 139.6 & 165 & 86 \\
& 333 & 522.8 & 132.9 & 297 & 81 \\
\hline
\end{tabular}

The curves of variation of $\mathrm{Ln} \mathrm{i}_{\text {corr }}$ versus $1 / \mathrm{T}$ and $\mathrm{Ln}\left(\mathrm{i}_{\mathrm{corr}} / \mathrm{T}\right)$ versus $1 / \mathrm{T}$ are recorded in Fig. 8 and Fig. 9, respectively.

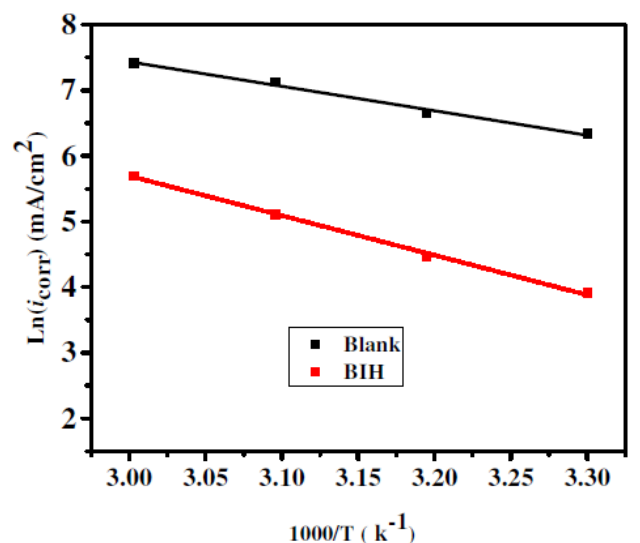

Figure 8. Plots for carbon steel in a $1.0 \mathrm{M} \mathrm{HCl}$ solution, and $1.0 \mathrm{M} \mathrm{HCl}+5 \times 10^{-3} \mathrm{M}$ of $\mathrm{BIH}$.

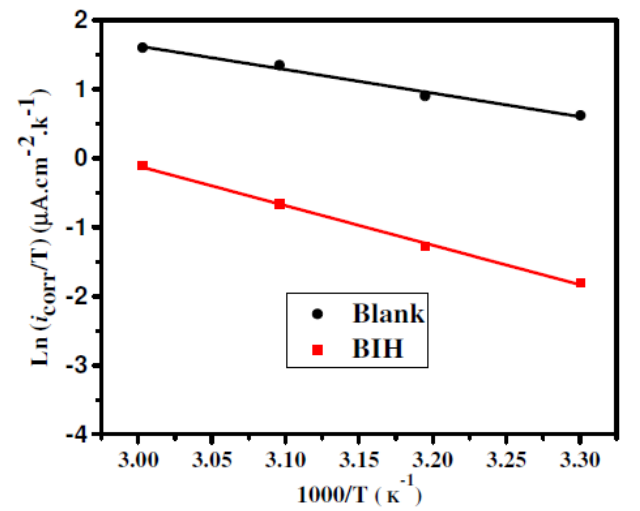

Figure 9. Transition state plots for carbon steel in a $1.0 \mathrm{M} \mathrm{HCl}$ solution, and $1.0 \mathrm{M} \mathrm{HCl}$ $+5 \times 10^{-3} \mathrm{M}$ of $\mathrm{BIH}$. 
The curves obtained in the form of lines obey the Arrhenius law, thus satisfying the relations 11 and 12, and all the regression coefficients are close to 1 . The activation parameters in BIH absence and presence are summarized in Table 5.

According to the data in Table 5, $\mathrm{E}_{\mathrm{a}}$ values determined in solutions with $\mathrm{BIH}$ are higher than those in the inhibitor absence, suggesting that the energy barrier of the corrosion reaction increased, which means that carbon steel dissolution is difficult [51]. High $E_{a}$ values are generally associated with low corrosion rates, while low $\mathrm{E}_{\mathrm{a}}$ values are associated with high corrosion rates. However, $\Delta \mathrm{H}_{\mathrm{a}}$ positive sign reflects the endothermic nature of the carbon steel dissolution process, suggesting that this is slow [52] in the inhibitor presence.

On the other hand, Table 5 shows that $\Delta \mathrm{Sa}$ values increased in the inhibitor presence, compared to the blank solution, which means that an increase in disorder took place during the course of the transition from the reactant to the activated complex, during the corrosion process [53-54].

Table 5. Corrosion kinetic parameters for carbon steel in a $1.0 \mathrm{M} \mathrm{HCl}$ solution, in the presence and absence of $5 \times 10^{-3} \mathrm{M}$ of BIH.

\begin{tabular}{ccccc}
\hline Inhibitor & $\begin{array}{c}\mathbf{E}_{\mathbf{a}} \\
(\mathbf{k J} / \mathbf{m o l})\end{array}$ & $\begin{array}{c}\Delta \mathbf{H}_{\mathbf{a}} \\
(\mathbf{k J} / \mathbf{m o l})\end{array}$ & $\begin{array}{c}\Delta \mathbf{S}_{\mathbf{a}} \\
\left(\mathbf{J ~ m o l}^{-1} \mathbf{K}^{-\mathbf{1}}\right)\end{array}$ & $\begin{array}{c}\mathbf{E}_{\mathbf{a}} \\
-\Delta \mathbf{H}_{\mathbf{a}}\end{array}$ \\
\hline Blank & 31.00 & 28.36 & -98.8 & 2.64 \\
$5 \times 10^{-3} \mathrm{M}$ BIH & 50.25 & 47.61 & -55.56 & 2.64 \\
\hline
\end{tabular}

\section{Adsorption isotherm}

Adsorption isotherm is one of the most important topics in the field of corrosion, because the organic molecules reduce metallic corrosion by adsorption at the metal/solution interface, and the adsorption isotherm can give important information about the interface mechanism between the inhibitor and the metal surface. As it is known, the adsorption process of the inhibitor is a displacement reaction, where the adsorbed water molecule is being removed from the metal surface, according to the following process:

$$
\mathrm{Org}_{(\mathrm{sol})}+x \mathrm{H}_{2} \mathrm{O}_{\text {(ads) }} \leftrightarrow \mathrm{Org}_{\text {(ads) }}+x \mathrm{H}_{2} \mathrm{O}_{\text {(sol) }}
$$

where $\operatorname{Org}_{(\text {sol })}$ and $\operatorname{Org}_{(\text {ads })}$ are the organic molecules in the aqueous solution, and the ones adsorbed onto the metallic surface, respectively, $\mathrm{H}_{2} \mathrm{O}_{(\text {ads })}$ is the water molecules on the metallic surface, and $\mathrm{x}$ the number of water molecules replaced by the organic molecules [55]. When the equilibrium of the process described in this equation is reached, it is possible to obtain different expressions of the adsorption isotherm plots, and thus, the surface coverage degree $(\theta)$ can be plotted as a function of the inhibitor concentration under testing [56].

In order to assess what adsorption behaviors are likely to occur onto the carbon steel surface, the adsorption isotherms were calculated. In our present study, several adsorption isotherms, namely, Langmuir, Temkin and Frumkin isotherms were tested to find the best fit. The results showed that Langmuir isotherm gave the best fit, with the regression coefficient value closer to unity $\left(\mathrm{R}^{2}=0.9999\right)$, and the slope nearly 1 . However, the surface coverage $(\theta)$ rate for different concentrations in acidic media was evaluated by the potentiodynamic 
polarization $(\eta(\%) / 100)$ method. According to the Langmuir isotherm, the degree of surface coverage $(\theta)$ is related to the inhibitor concentration $(C)$, by the following way [57]:

$$
\frac{C_{\text {inh }}}{\theta}=\frac{1}{K_{\text {ads }}}+C_{\text {inh }}
$$

where $\theta$ is the surface coverage degree, $\mathrm{C}_{\mathrm{inh}}$ is the inhibitor concentration in the electrolyte and $\mathrm{K}_{\mathrm{ads}}$ is the equilibrium constant of the adsorption process. Using $\mathrm{K}_{\mathrm{ads}}$ values, $\Delta \mathrm{G}_{\text {ads }}^{\mathrm{o}}$ values were evaluated using the following equation [58]:

$$
\Delta G_{\mathrm{ads}}^{\circ}=-R T \ln \left(K_{\mathrm{ads}} \times 55.5\right)
$$

where $\mathrm{R}$ is the universal gas constant, $\mathrm{T}$ is the thermodynamic temperature and 55.5 is the water concentration in the solution.

Plots of $\mathrm{C}_{\mathrm{inh}} / \theta$ as a function of $\mathrm{C}_{\mathrm{inh}}$ yielded a straight line; the experimental (points) and calculated isotherms (line) are plotted in Fig. 10. From the intercepts of Fig. $10, K_{a d s}$ values were calculated. Table 6 summarized $K_{a d s}$ and $\Delta G_{\text {ads }}^{\circ}$ values.

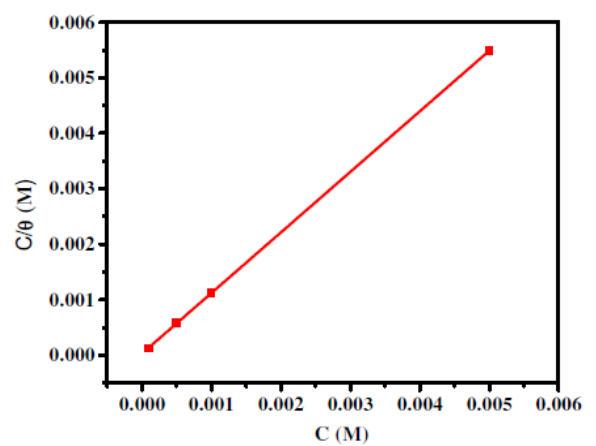

Figure 10. Plots of BIH Langmuir adsorption isotherm on the carbon steel surface, at $303 \mathrm{~K}$.

Table 6. The adsorption parameters for carbon steel corrosion in a $1.0 \mathrm{M} \mathrm{HCl}$ solution, at $303 \mathrm{~K}$.

\begin{tabular}{ccccc}
\hline Inhibitor & Slope & $\boldsymbol{K}_{\text {ads }}\left(\mathbf{M}^{-\mathbf{1}}\right)$ & $\boldsymbol{R}^{\mathbf{2}}$ & $\Delta \mathbf{G}_{\text {ads }}^{\circ}(\mathbf{k J} / \mathbf{m o l})$ \\
\hline BIH & 1.09 & 37533 & 0.9999 & -36.63 \\
\hline
\end{tabular}

It can be seen from Table 6 that $\mathrm{K}_{\mathrm{ads}}$ value is high, indicating that the inhibitor is easily and strongly adsorbed onto the metal surface, which leads to a better inhibition performance. In our case, BIH strong interaction with carbon steel can be attributed to the presence of heteroatoms, such as $\mathrm{N}$ and $\mathrm{O}$, and $\pi$-electrons in the inhibitor molecule [59]. $\Delta \mathrm{G}_{\text {ads }}^{\circ}$ value is $-36.63 \mathrm{~kJ} \mathrm{~mol}^{-1}$ in our measurements. Generally, free energy standard values from $-20 \mathrm{~kJ} \mathrm{~mol}^{-1}$, or less negative, are associated with an electrostatic interaction between the charged molecules and the charged metal surface (physical adsorption) [60]; those from $-40 \mathrm{~kJ} \mathrm{~mol}^{-1}$, or more negative, involve a load sharing or transfer of inhibitor molecules to the metal surface, forming a coordinate covalent bond (chemisorption) [61]. Likewise, in the present study, the calculated $\Delta \mathrm{G}_{\text {ads }}^{\circ}$ values are between 20 and 
$40 \mathrm{~kJ} \mathrm{~mol}^{-1}$. Consequently, BIH adsorption onto the carbon steel surface involves the combination of chemisorption and physisorption [62].

\section{Quantum chemical study}

The density function theory (DFT) has been used to analyze the characteristics of the inhibitor/surface mechanism, and to describe the structural nature of the inhibitor on the corrosion process. Recently, the quantum chemical study was performed to establish a correlation between the molecular structure of the inhibitor and inhibition efficiency. In the present study, various quantum chemical parameters, such as $\mathrm{E}_{\text {HOMo, }} \mathrm{E}_{\mathrm{Lumo}}$ and the energy gap $\Delta \mathrm{E}$ (ELumo $\mathrm{E}_{\text {Hомо }}$ ), were obtained for the BIH molecule, to predict their activity towards the metal surface. These quantum chemical parameters were determined from the geometrically optimized molecule, and are given in Table 7. The optimized and frontier molecular orbital structures of BIH are shown in Fig. 11.

Table 7. Quantum chemical parameters for BIH, calculated using B3LYP/ 6-31G (d,p).

\begin{tabular}{cccccc}
\hline & & & & & \\
$\mathbf{E}_{\text {номо }}(\mathbf{e V})$ & $\mathbf{E}_{\text {Luмо }}(\mathbf{e V})$ & $\boldsymbol{\Delta} \mathbf{E}_{\text {gap }}(\mathbf{e V})$ & $\chi(\mathbf{e V})$ & $\boldsymbol{\eta}(\mathbf{e V})$ & $\Delta \mathbf{N}$ \\
\hline-5.8937 & - & 4.1663 & 3.8105 & 2.0831 & 0.4222 \\
\hline
\end{tabular}

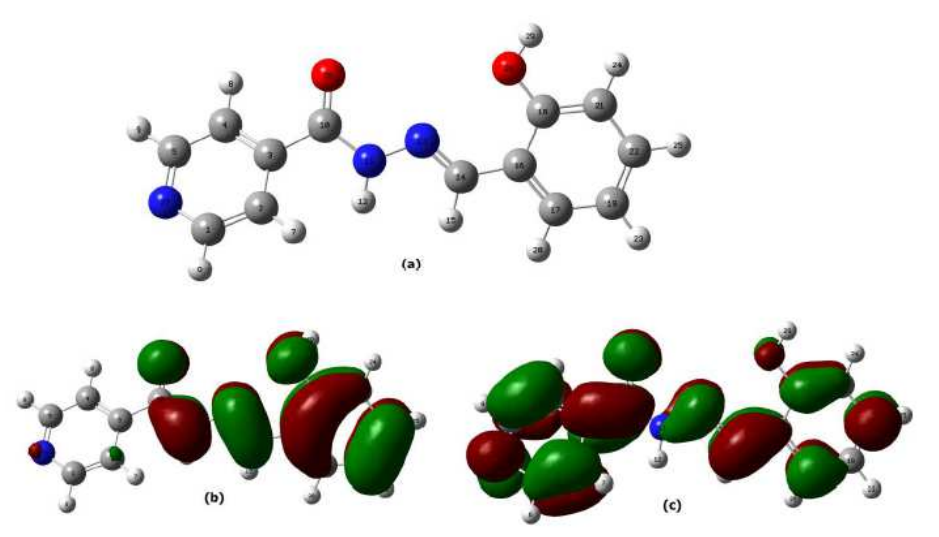

Figure 11. (a) Optimized molecular structure, (b) frontiers orbital's distribution, HOMO and (c) LUMO, of the inhibitor.

Based on the frontier molecular orbital theory, the reactants reaction mainly occurred on the highest occupied molecular orbital (HOMO) and lowest unoccupied molecular orbital (LUMO). Therefore, it's indispensable to analyze the electron density distribution in the HOMO and LUMO orbitals of the inhibitor molecule. This HOMO and LUMO orbitals distribution is a critical tool to predict the reactivity and, consequently, the ability of the tested compound to adsorb onto the carbon steel surface. Higher $\mathrm{E}_{\text {HOMо }}$ values indicate that the molecule has a higher tendency to donate electrons to appropriate acceptor molecules with low energy empty molecular orbital, and lower ELUMO values, suggesting that the molecule easily accepts electrons from the donor molecules [63]. The lower $\Delta \mathrm{E}$ value is another important molecular parameter which favors higher inhibitor performance. 
The BIH molecule adsorption from the aqueous solution can be regarded as a quasi-substitution process between $\mathrm{BIH}$ in the aqueous phase [BIH (sol)] and water molecules at the electrode surface $\left[\mathrm{H}_{2} \mathrm{O}(\mathrm{ads})\right]$. In its turn, the $\Delta \mathrm{E}$ energy gap between LUMO (ability to accept) and HOMO (ability to donate) had a value of $4.1663 \mathrm{eV}$. It reflects $\mathrm{BIH}$ higher inhibition efficiency, because lower $\Delta \mathrm{E}$ causes the improvement on the molecule reactivity, which facilitates adsorption. The fraction of electrons transferred $(\Delta \mathrm{N})$ from the inhibitor to the carbon steel surface was also calculated. It was reported that $\Delta \mathrm{N}$ value measures the ability of a chemical compound to transfer its electrons to metal, if $\Delta \mathrm{N}>0$ and, vice versa, if $\Delta N<0$ [64-65]. In this study, the positive value of $\Delta N$ (0.4222) presented in Table 7 suggests the high capability of BIH to donate electrons to the carbon steel surface.

Furthermore, from Fig. 11, it could be seen that BIH has similar HOMO and LUMO distributions, which were all located on the entire molecular structure. This is due to oxygen and nitrogen atoms presence, together with several $\pi$-electrons on the entire molecule. In this study, the compound is the electrons donator, and the iron surface is the acceptor. The unoccupied d orbitals of Fe atoms can accept electrons from the inhibitor molecule, to form a coordinate bond. Also, the inhibitor molecule can accept electrons from Fe atom, with its anti-bonding orbitals, to form a back-donating bond.

It is also reported in literature that Mulliken charges can be used for the determination of possible adsorption centers of the inhibitors [66-67]. Mulliken charges, according to the numeration of corresponding atoms, are shown in Fig. 12. It is evident from this figure that the inhibitor had a considerable excess of negative charge around nitrogen, oxygen and some carbon atoms, indicating that these are the coordinating sites of the inhibitor.

\section{Monte Carlo simulations}

Monte Carlo simulations were carried out to better understand the interaction between $\mathrm{BIH}$ and the Fe (llll 110$)$ surface, because it provides some essential parameters, such as the adsorption energy. In our present study, the Monte Carlo simulation calculation was used to find the lowest energy for the whole system. Fig. 13 represents the most stable low energy configuration for BIH adsorption on the Fe (lllll 110$)$ surface obtained through the Monte Carlo simulations.

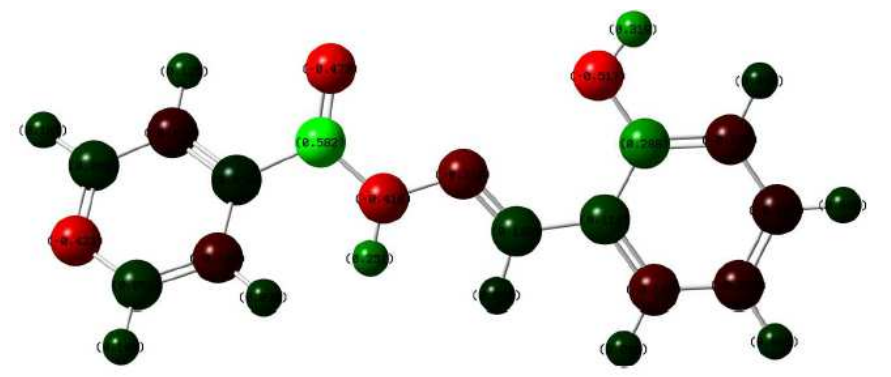

Figure 12. The Mulliken charge distribution of BIH inhibitor. 


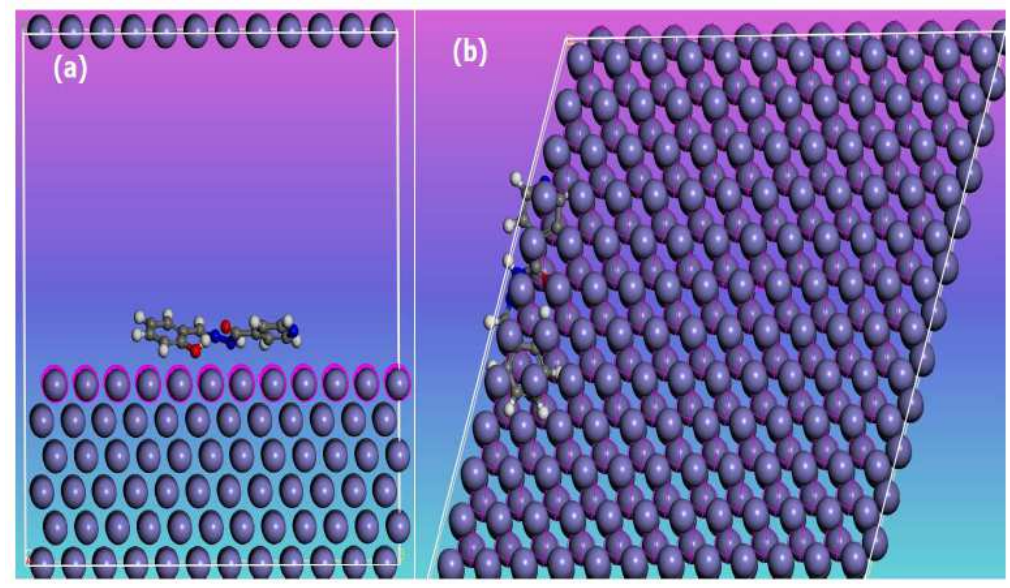

Figure 13. (a) Side and (b) top views of the most stable low energy configuration for the inhibitor adsorption onto the Fe (llll 10$)$ surface, obtained through the Monte Carlo simulation for BIH.

It is by and large recognized that the essential phenomenon of carbon steel corrosion inhibition is adsorption. So, the adsorption energy can furnish us with immediate information about inhibitors efficiency. The results depicted in Table 8 show that the benzohydrazide derivative associated with high negative adsorption energy values resulted in strong interactions between metal and the BIH molecule [68].

By inspection of Fig. 13, it could be observed that BIH nearly adsorbed onto the Fe $\left(\begin{array}{lll}1 & 1 & 0\end{array}\right)$ surface, where chemical interactions can possibly occur through reactive sites in the molecule, as interpreted in the experimental and theoretical study. In this case, the BIH molecule protects the carbon steel surface from the aggressive medium, by adsorbing onto the Fe (lll 110$)$ surface in the possible nearby planar form, reducing the carbon steel dissolution [69].

Table 8. Outputs and descriptors calculated by the Monte Carlo simulation for BIH lowest adsorption configurations on the Fe (llll 110$)$ surface (in kcal/mol).

\begin{tabular}{cc}
\hline \multicolumn{1}{c}{ System } & Adsorption energy \\
\hline $\mathrm{Fe}\left(\begin{array}{lll}1 & 1 & 0\end{array}\right) / \mathbf{B I H}$ & -103.931 \\
\hline
\end{tabular}

\section{Conclusion}

In the present investigation, it can be concluded that the $\mathrm{BIH}$ compound shows excellent inhibition properties for carbon steel corrosion in a $1.0 \mathrm{M} \mathrm{HCl}$ solution, at $303 \mathrm{~K}$, and the inhibition efficiency increases with higher BIH concentrations, while it slightly decreases with rises in temperature. The inhibitor efficiencies determined by weight loss, Tafel polarization and EIS methods are in good agreement. Polarization measurements show that BIH inhibits both anodic and cathodic processes, indicating that this is a mixed type corrosion inhibitor. The EIS measurements showed that charge transfer resistance $\left(R_{c t}\right)$ increased, and that the double layer capacitance $\left(\mathrm{C}_{\mathrm{dl}}\right)$ decreased in the inhibitor presence, 
suggesting the inhibitor molecule adsorption onto the carbon steel surface. BIH adsorption onto the carbon steel surface in a hydrochloric acid solution obeyed the Langmuir adsorption isotherm. The density distributions of the frontier molecular orbitals (HOMO and LUMO) indicate that the studied derivative adsorbed through the active centers of $\mathrm{N}$ and $\mathrm{O}$ atoms and $\pi$ electrons of the hydroxybenzylidene and phenyl rings. Monte Carlo simulations study showed that BIH adsorbed onto the Fe $\left(\begin{array}{lll}1 & 1 & 0\end{array}\right)$ surface in a near flat orientation, and the adsorption energy value of the equilibrium configuration supports the experimental inhibition efficiency of the compound.

\section{References}

1. El Makrini B, Lgaz H, Toumiat K, et al. Res J Pharm Biol Chem Sci. 2016;7(5):2277.

2. Adardour L, Lgaz H, Salghi R, et al. Pharm Lett. 2016;8(4):212.

3. Lgaz H, Saadouni M, Salghi R, et al. Pharm Lett. 2016;8(18):167.

4. Lgaz H, Anejjar A, Salghi R, et al. Int J Corros Scale Inhib. 2016;5(3):209.

5. Bousskri A, Anejjar A, Salghi R, et al. J Mater Environ Sci. 2016;7(11):4269.

6. Saadouni M, Larouj M, Salghi R, et al. Pharm Lett. 2016;8(4):65.

7. Adardour L, Lgaz H, Salghi R, et al. Pharm Lett 2016;8(4):173.

8. Adardour L, Lgaz H, Salghi R, et al. Pharm Lett. 2016;8(4):126.

9. El Makrini B, Toumiat K, Lgaz H, et al. Res J Pharm Biol Chem Sci 2016;7(5):2286.

10. Toumiat K, El Aoufir Y, Lgaz H, et al. Res J Pharm Biol Chem Sci 2016;7(5):1210.

11. Saadouni M, Larouj M, Salghi R, et al. Pharm Lett 2016;8(4):96.

12. El Makrini B, Larouj M, Lgaz H, et al. Pharma Chem 2016;8(2):227.

13. Lgaz H, Salghi R, Larouj M, et al. J Mater Environ Sci 2016;7(12):4471.

14. Lgaz H, Benali O, Salghi R, et al. Pharma Chem. 2016;8(2):172.

15. Lgaz H, Salghi R, Jodeh S, et al. Appl J Environ Eng Sci. 2015;1(2):57.

16. Bousskri A, Anejjar A, Lgaz H, et al. Appl J Environ Eng Sci. 2015;1(1):9.

17. Lgaz H, Toumiat K, Jodeh S, et al. Appl J Environ Eng Sci. 2016;2(2):72.

18. Bousskri A, Lgaz H, Jodeh S, et al. Appl J Environ Eng Sci. 2016;2(1):1.

19. Aljourani J, Golozar M, Raeissi K. Mater Chem Phys. 2010;121(1):320.

20. Abboud Y, Abourriche A, Saffaj T, et al. Mater Chem Phys. 2007;105(1):1.

21. Goulart CM, Esteves-Souza A, Martinez-Huitle CA, et al. Corros Sci. 2013;67:281.

22. Obot I, Obi-Egbedi N, Umoren S. Corros Sci. 2009;51(8):1868.

23. Döner A, Solmaz R, Özcan M, et al. Corros Sci. 2011;53(9):2902.

24. Obot I, Gasem Z. Corros Sci. 2014;83:359.

25. Becke AD. J Chem Phys. 1993;98(7):5648.

26. Frisch M, Trucks G, Schlegel H, et al. Gaussian 09. revision D. 012009.

27. Pearson RG. Inorg Chem. 1988;27(4):734.

28. Sastri V, Perumareddi J. Corrosion. 1997;53(8):617.

29. Martinez S. Mater Chem Phys. 2003;77(1):97. 
30. Cao Z, Tang Y, Cang H, et al. Corros Sci. 2014;83:292.

31. Kokalj A. Chem Phys. 2012;393(1):1.

32. Saha SK, Murmu M, Murmu NC, et al. J Mol Liq. 2016;224:629.

33. Materials Studio. Revision 6.0. Accelrys Inc. San Diego: USA; 2013.

34. Eivani AR, Zhou J, Duszczyk J. Comput Mater Sci. 2012;54:370.

35. Hmamou DB, Salghi R, Zarrouk A, et al. J Environ Chem Eng. 2015;3(3):2031.

36. Kaya S, Tüzün B, Kaya C, et al. J Taiwan Inst Chem Eng. 2016;58:528.

37. Obot I, Obi-Egbedi N. Curr Appl Phys. 2011;11(3):382.

38. Quraishi M, Ahmad S, Ansari M. Br Corros J. 1997;32(4):297.

39. Bentiss F, Jama C, Mernari B, et al. Corros Sci. 2009;51(8):1628.

40. Ferreira E, Giacomelli C, Giacomelli F, et al. Mater Chem Phys. 2004;83(1):129.

41. Parveen M, Mobin M, Zehra S. RSC Adv. 2016;6(66):61235.

42. Krishnaveni K, Ravichandran J. J Electroanal Chem. 2014;735:24.

43. Yadav M, Behera D, Kumar S. Surf Interf Anal. 2014;46(9):640.

44. Popova A, Christov M, Vasilev A. Corros Sci. 2007;49(8):3290.

45. Krishnaveni K, Ravichandran J. J Electroanal Chem. 2014;735:24.

46. Banerjee S, Srivastava V, Singh M. Corros Sci. 2012;59:35.

47. Bentiss F, Lebrini M, Lagrenée M. Corros Sci. 2005;47(12):2915.

48. Xu B, Yang W, Liu Y, et al. Corros Sci. 2014;78:260.

49. Xu B, Liu Y, Yin X, et al. Corros Sci. 2013;74:206.

50. Zhang S, Tao Z, Liao S, et al. Corros Sci. 2010;52, 3126.

51. Gomma GK, Wahdan MH. Mater Chem Phys. 1995;39(3):209.

52. Gerengi H, Darowicki K, Bereket G, et al. Corros Sci. 2009;51(11):2573.

53. Singh AK, Quraishi M. Corros Sci. 2011;53(4):1288.

54. Khamis E, Hosny A, Elhadary S. Afinidad 1995;52(456):95.

55. Solmaz R. Corros Sci. 2010;52(10):3321.

56. Labjar N, Bentiss F, Lebrini M, et al. Int J Corros. 2011;2011.

57. Langmuir I. J Am Chem Soc. 1917;3(9):1848.

58. Flis J, Zakroczymski T. J Electrochem Soc. 1996;143(8):2458.

59. Özkır D, Kayakırılmaz K, Bayol E, et al. Corros Sci. 2012;56:143.

60. Yurt A, Bereket G, Kivrak A, et al. J Appl Electrochem. 2005;35(10):1025.

61. Saliyan VR, Adhikari AV. Corros Sci. 2008;50(1):55.

62. Behpour M, Ghoreishi S, Soltani N, et al. Corros Sci. 2008;50(8):2172.

63. Xia S, Qiu M, Yu L, et al. Corros Sci. 2008;50(7):2021.

64. Kovačević N, Kokalj A. Corros Sci. 2011;53(3):909.

65. Kokalj A. Electrochim Acta 2010;56(2):745.

66. Kandemirli F, Sagdinc S. Corros Sci. 2007;49(5):2118.

67. Hasanov R, Sadıkoğlu M, Bilgiç S. Appl Surf Sci. 2007;253(8):3913.

68. Khaled K, Amin MA. Corros Sci. 2009;51(9):2098.

69. Zhang Z, Tian N, Huang X, et al. RSC Adv. 2016;6(27):22250. 